\title{
Spatial Pattern and Forecast Analysis of Urbanization Growth Rates in Henan: 2011-2015
}

\author{
Kaiguang Zhang*, Mingting Ba and Hongling Meng \\ Institute of 3S Technology, Zhengzhou Normal University, Zhengzhou 450044, China \\ ${ }^{*}$ Corresponding author
}

\begin{abstract}
Urbanization growth rate is the conversion speed of agricultural population to non-agricultural population along with the regional population structure transformation process caused by productivity development, modern scientific and technological application and industrial structure adjustment. In the paper, the geospatial-temporal characteristics and the evolution patterns of urbanization growth rates were studied by using spatial statistical analysis methods, and the future development trends were forecasted by Logistic curve model in Henan province from 20112015. The results show that, the urbanization growth rates of all cities are gradually slowing down, there have been rapid increasing in a few local regions, but the overall distributions are tending to balance. In the 4 periods, the urbanization growth rates and the urbanization levels are inverse proportion. The spatial distributions of urbanization growth rates show northsouth high and intermediate low, and gradually converging from north and south regions toward each other. In the next 5 years, the province urbanization growth rate of environmental loading and environmental endurance exist certain promotion space, the urbanization levels will continue to maintain a rapid growth, the growth rates will be slow down comparing with the past 5 years. There are some certain gaps in the natural growth rates and Thirteen Five Planning Objectives of the province.
\end{abstract}

Keywords-urbanization growth rate; iterative clustering analysis; logistic curve model; forecast analysis; spatial pattern

\section{INTRODUCTION}

Urbanization is the transformation process of agricultural society to non-agricultural society, along with productivity development, scientific and technological application and industrial structure adjustment $[1,2]$. Urbanization growth rate describes how fast an agricultural society turning into nonagricultural society process, reflects the expansion process of a city, including the increase of city resident population proportion to the region's total population, the increase number of cities and towns, the expansion of built area $[3,4]$. Urbanization growth rate is affected by many factors, such as economy, society, politics, history, geography, system, policy and so on. In recent years, the researches on urbanization growth rate mainly focus on the coordination of urbanization and economic development, achieve some valuable results [58].

Henan province is located in the middle of China, on the middle and lower reaches of Yellow River, is agricultural and populous province. The rationality of national economic structure in some aspects lags behind the other province. Large agricultural province, large number of rural population, too concentration of heavy industrial distribution are the main reasons for the low of urbanization level and urbanization growth rate. By 2015, the province urbanization level is lower than the national level of 10.9 percentage points.

This paper uses spatial statistical analysis methods to study the geospatial-temporal characteristics and evolution patterns of urbanization growth rates, and forecasts the future development trend of urbanization growth rates for all cities in the province, in order to correctly understand the spatial distribution characteristics of urbanization growth rates, provide a useful reference for formulating coordinated regional development policy. Research data are mainly from Henan Statistical Yearbook (2011-2015), the spatial data are derived from Henan GIS database.

\section{RESEARCH METHODS}

\section{A. Iterative Clustering Analysis}

Cluster analysis is a useful tool to analyze the clustering characteristics of spatial phenomenon, which divides samples into different classes with similar attributes according to the similarity degree $\boldsymbol{C}_{\boldsymbol{i j}}$ between samples and the distance $\boldsymbol{D}_{\boldsymbol{i}}$ between classes. The formation of sub-classes is the result of the operation of spatial geographic system, reveals the spatial distribution geographic mechanism.

$$
C_{i j}=\sum_{t=1}^{n}\left(x_{t i}-\overline{x_{i}}\right)\left(x_{t j}-\overline{x_{j}}\right) / \sigma_{i} \sigma_{j} ; D_{i j}=\sum_{k=1}^{n} \sum_{t=1}^{n}\left(x_{k i}-\overline{x_{i}}\right)\left(x_{t j}-\overline{x_{j}}\right),
$$

where $x_{i}, \overline{x_{i}},(\boldsymbol{n}-1) \sigma_{i}$ are sample value, sample mean and sample standard deviation respectively.

Iterative clustering analysis, analyzes a continuous sample observation through the sample sequence stepping and truncating, is an important method to observe the sample level and trends in the sequence.

\section{B. Logistics Curve Model}

Logistics curve describes the natural growth law of biological population, the urbanization in a region is a self organization evolution process, the urbanization growth rate conforms to the logistic cumulative distribution characteristics, therefore, which can be used to describe the developing trends of urbanization growth rate, and forecast the future direction of urbanization growth rate in a region $[9,10,11]$. 
The differential form of Logistics curve equation is

$$
\frac{d N}{d t}=r N\left(1-\frac{N}{K}\right), N=\frac{K}{1+\exp \{a-r t\}},
$$

where $N$ is the discrete variables of urbanization growth rate, $t$, $\boldsymbol{r}$ and $\boldsymbol{K}$ are time series, natural growth rate and environmental loading respectively.

In the analysis, $\boldsymbol{K}$ is estimated by using 4 consecutive sample observation values,

$$
K=\frac{N_{1} N_{4}\left(N_{2}+N_{3}\right)-N_{2} N_{3}\left(N_{1}+N_{4}\right)}{N_{1} N_{4}-N_{2} N_{3}},
$$

$a, r$ are the least squares estimation by the linear regression .

$$
y=\ln \frac{K-N}{N}=a-r t .
$$

\section{SPATIAL-TEMPORAL EVOLUTION PATTERN OF Urbanization Growth Rates in Henan Province}

\section{A. Digital Characteristics of Urbanization Growth Rates in Henan Province}

For the province, in the 4 periods (Table I), the ranges have been gradually increasing, but the variance have been

TABLE I. URBANIZATION GROWTH RATES IN HENAN PROVINCE(2011-2015)

\begin{tabular}{|ll|l|l|l|l|l|l|l|c|c|c|}
\hline & ZZ & KF & LY & PDS & AY & HB & XX & JZ & PY & XC & LH \\
\hline $11-12$ & 1.20 & 1.75 & 1.80 & 1.75 & 1.89 & 1.75 & 1.80 & 1.75 & 1.89 & 1.82 & 1.76 \\
\hline $13-14$ & 1.46 & 1.95 & 1.80 & 1.83 & 1.94 & 1.80 & 1.80 & 1.92 & 1.85 & 1.91 & 1.92 \\
\hline $13-14$ & 0.86 & 1.37 & 1.47 & 1.40 & 1.38 & 1.24 & 1.26 & 1.42 & 1.67 & 1.36 & 1.35 \\
\hline $14-15$ & 1.20 & 1.56 & 1.50 & 1.41 & 1.38 & 0.95 & 1.69 & 1.27 & 1.74 & 1.42 & 1.58 \\
\hline $11-12$ & SMX & NY & SQ & XY & ZK & ZMD & JY & Var & Rang & HN & China \\
\hline $13-14$ & 1.60 & 1.85 & 1.79 & 1.89 & 1.77 & 1.79 & 2.00 & 0.03 & 0.80 & 1.75 & 1.32 \\
\hline $13-14$ & 1.51 & 1.96 & 1.95 & 1.94 & 1.94 & 1.90 & 2.00 & 0.02 & 0.54 & 1.86 & 2.00 \\
\hline $14-15$ & 1.12 & 1.28 & 1.47 & 1.37 & 1.40 & 1.44 & 2.78 & 0.14 & 1.82 & 1.40 & 1.04 \\
\hline
\end{tabular}

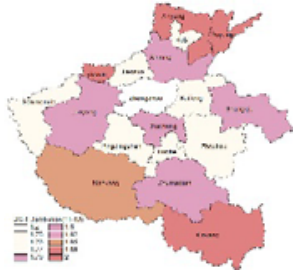

(a) $11-12$

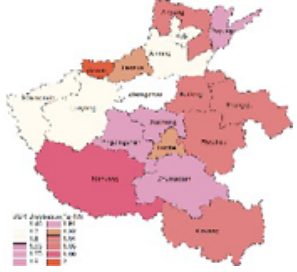

(b) $12-13$

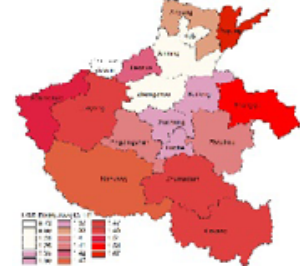

(c)13-14

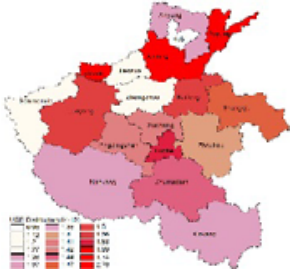

(d) $14-15$

FIGURE I. THE SPATIAL DISTRIBUTIONS OF URBANIZATION GROWTH RATES IN HENAN PROVINCE

gradually decreasing, which show the province urbanization growth rates gradually slowed down, at the same time, there are rapidly increase cities, but the overall tends to be balanced. With the city real estate index similar trend, the growth peak appears in the second period. In the first, third and fourth periods, the province urbanization growth rates are higher than the national average of $0.43,0.21$ and 0.36 percentage points respectively. In the second period, lower than the national average of 0.14 percentage points.

In the first period, all cities (except for Zhengzhou) are higher than the national average, Jiyuan ranks first in the province up to $2 \%, 14$ cities are higher than the provincial average. In the second period, Jiyuan is basically equivalent to the national average, the rest cities are lower than the national average, 14 cities are higher than the provincial average. In the third period, Jiyuan and Zhengzhou are lower than the national average, and the rest cities are higher than the national average,
Jiyuan is the lowest to $0.73 \%$, 9 cities are higher than the provincial average. In the fourth period, all cities (except for Hebi) are higher than the national average, Jiyuan ranks first as $2.78 \%, 8$ cities are higher than the provincial average. Overall, on 4 periods, urbanization growth rates and urbanization levels are in inverse proportion, the cities with high urbanization level have low urbanization growth rates, Jiyuan shocks larger, the rest cities grow in the basic smooth, Zhengzhou always has been lower than the provincial average.

From the view of spatial distribution (Figure I), in the first period, cities in the north and south parts have higher urbanization growth rates than in the central region, showing the north and south high and middle low. The period 2 remained the basic distribution characteristics of the last period, cities in the east part rise rapidly, and cities along highway S83 and south region are significantly higher than other regions. The period 3 remains the basic distribution characteristics of 
last 2 period, cities in the west part significantly improve, and cities along highway G30 and south region are significantly higher than other regions. In the fourth period, the basic distribution characteristics is contrary to that in the first period, except for cities as Zhengzhou, Jiaozuo, Sanmenxia and Hebi which maintain the lowest growth rates, the cities with low growth rates in the first period have changed into high growth rates cities.

Overall, in the 4 periods, the spatial distributions of urbanization growth rates show north-south high and intermediate low, and gradually converging from north and south regions toward intermediate region.

TABLE II. THE ITERATIVE CLUSTERING ANALYSIS OF URBANIZATION GROWTH RATES IN HENAN PROVINCE(2011-2015)

\begin{tabular}{|l|l|l|l|l|l|l|}
\hline & \multicolumn{1}{|c|}{ I III } & \multicolumn{1}{|c|}{ II } \\
\hline z1112 & 1.90 & AY,PY,JY,NY,XY & 1.80 & $\begin{array}{l}\text { HB,XX,JZ,SMX,LY,PDS,XC,LH, } \\
\text { KF,SQ,ZK,ZMD }\end{array}$ & 1.20 & ZZ \\
\hline z1213 & 2.00 & $\begin{array}{l}\text { AY,JZ,JY,KF,SQ,XC, } \\
\text { LH,ZK,ZMD,NY,XY }\end{array}$ & 1.80 & PY,HB,XX,LY,PDS & 1.46 & ZZ,SMX \\
\hline z1314 & 1.67 & $\begin{array}{l}\text { PY,AQ,SMX,LY,NY, } \\
\text { ZMD,XY }\end{array}$ & 1.24 & $\begin{array}{l}\text { AY,HB,XX,JZ,KF,XC, } \\
\text { PDS,LH,ZK }\end{array}$ & 0.73 & ZZ,JY \\
\hline z1415 & 2.78 & JY & 1.37 & $\begin{array}{l}\text { AY,PY.XX,LY,KF,PDS,XC,LH,ZK, } \\
\text { ZMD,XY,SQ }\end{array}$ & 0.95 & $\begin{array}{l}\text { HB,JY,ZZ, } \\
\text { SMX,NY }\end{array}$ \\
\hline
\end{tabular}

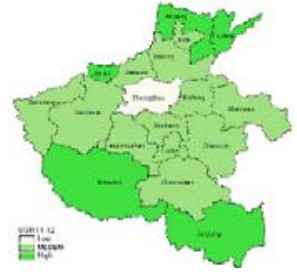

(a) $11-12$

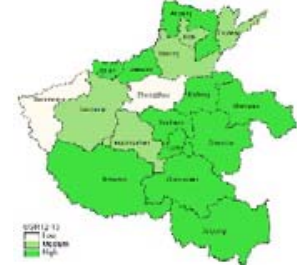

(b) $12-13$

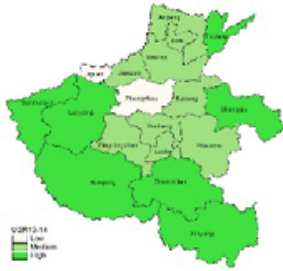

(c)13-14

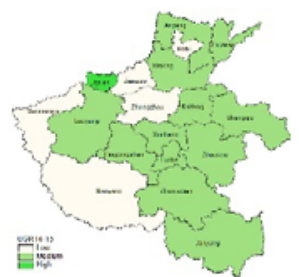

(d)14-15

FIGURE II. THE CLASS SPATIAL DISTRIBUTIONS OF URBANIZATION GROWTH RATES IN HENAN PROVINCE

TABLE III. THE FORECAST ANALYSIS OF URBANIZATION GROWTH RATES IN HENAN PROVINCE(2016-2020)

\begin{tabular}{|c|c|c|c|c|c|c|c|c|c|c|c|}
\hline & ZZ & KF & LY & PDS & AY & HB & XX & JZ & PY & XC & LH \\
\hline $\mathrm{K}$ & 76 & 51 & 61 & 55 & 50 & 56 & 68 & 58 & 58 & 52 & 55 \\
\hline $\mathrm{a}$ & -1.61 & -0.87 & -0.95 & -1.10 & -1.16 & -1.72 & -0.43 & -1.43 & -0.17 & -1.12 & -0.88 \\
\hline $\mathrm{r}$ & 0.14 & 0.19 & 0.16 & 0.20 & 0.25 & 0.37 & 0.10 & 0.27 & 0.13 & 0.22 & 0.17 \\
\hline $\mathrm{R} * \mathrm{R}$ & 0.99 & 1.00 & 1.00 & 1.00 & 1.00 & 1.00 & 1.00 & 1.00 & 1.00 & 1.00 & 1.00 \\
\hline 1617 & 0.82 & 1.08 & 1.16 & 0.99 & 0.86 & 0.47 & 1.37 & 0.77 & 1.54 & 0.92 & 1.13 \\
\hline 1718 & 0.73 & 0.93 & 1.03 & 0.84 & 0.69 & 0.33 & 1.31 & 0.60 & 1.46 & 0.76 & 1.00 \\
\hline 1819 & 0.65 & 0.80 & 0.92 & 0.71 & 0.56 & 0.23 & 1.24 & 0.47 & 1.37 & 0.63 & 0.87 \\
\hline 1920 & 0.58 & 0.68 & 0.81 & 0.59 & 0.44 & 0.16 & 1.17 & 0.37 & 1.28 & 0.51 & 0.76 \\
\hline & SMX & NY & SQ & XY & ZK & ZMD & JY & HN & HN75 & HN80 & \\
\hline $\mathrm{K}$ & 55 & 44 & 43 & 46 & 41 & 43 & 69 & 52 & 75 & 80 & \\
\hline $\mathrm{a}$ & -1.37 & -1.09 & -0.78 & -1.03 & -0.89 & -0.81 & -0.94 & -1.09 & -0.09 & 0.04 & \\
\hline $\mathrm{r}$ & 0.24 & 0.30 & 0.24 & 0.26 & 0.26 & 0.24 & 0.15 & 0.22 & 0.08 & 0.08 & \\
\hline $\mathrm{R} * \mathrm{R}$ & 1.00 & 1.00 & 1.00 & 1.00 & 1.00 & 1.00 & 0.94 & 1.00 & 1.00 & 0.995 & \\
\hline 1617 & 0.79 & 0.75 & 1.00 & 0.87 & 0.88 & 0.97 & 1.30 & 0.94 & 1.45 & 1.48 & \\
\hline 1718 & 0.64 & 0.58 & 0.83 & 0.70 & 0.71 & 0.81 & 1.16 & 0.78 & 1.42 & 1.46 & \\
\hline 1819 & 0.51 & 0.44 & 0.68 & 0.56 & 0.56 & 0.66 & 1.03 & 0.65 & 1.38 & 1.43 & \\
\hline 1920 & 0.41 & 0.33 & 0.55 & 0.44 & 0.45 & 0.54 & 0.91 & 0.54 & 1.34 & 3.40 & \\
\hline
\end{tabular}

B. Classification Characteristic of Urbanization Growth Rates in Henan Province

Using iterative clustering analysis method on the urbanization growth rates for the 4 periods, the urbanization growth rates of all cities in Henan province, by all combinations of stepping and truncating, can be divided into 3 classes (Table II) as high(I), medium(II) and low(III).From Figure II, it can be seen, in the first period, cities in class I are mainly distributed in the northern and southern marginal regions, inward contraction is class II, then the class III. In the second period, cities in class I are mainly distributed in the 
eastern and southern regions, as well as the northeast marginal regions, cities in class II and class III distribute on the province northeast to southwest axis line. In the third period, cities in class I are mainly distributed in the southwest and northeast marginal regions, cities in class II and class III distribute on the province northwest to southeast axis line. In the fourth period, class I contains only one city (Jiyuan), cities in class II are mainly distributed in the east part of the province.

Zhengzhou has always belonged to class III, the slowest urbanization growth rate class in the 4 periods. The urbanization growth rates of Jiyuan in first, second and fourth periods is in class I, the fastest urbanization growth rate class, but in the third period falls into class III. The urbanization growth rates of Xinxiang and Pingdingshan have been maintained at the province average. The cities, as Kaifeng, Luoyang, Luohe, Zhoukou, Xuchang, Shangqiu, Zhumadian, Anyang, Xinyang, have always been maintained higher level, but Jiaozuo and Xinyang have some weakening trend.

\section{Forecast Analysis of Urbanization Growth Rates in Henan Province}

With the development of social productive forces, the progress of science and technology as well as the adjustment of industrial structure, the urbanization development will continue to promote in the future. Using (2), (3) and (4), Logistic curve equation of each city is estimated, each city urbanization growth rates as well as the province urbanization growth rates in the next five years are forecasted, the results are shown in Table III, in which $\mathrm{R} * \mathrm{R}$ is the model residuals.

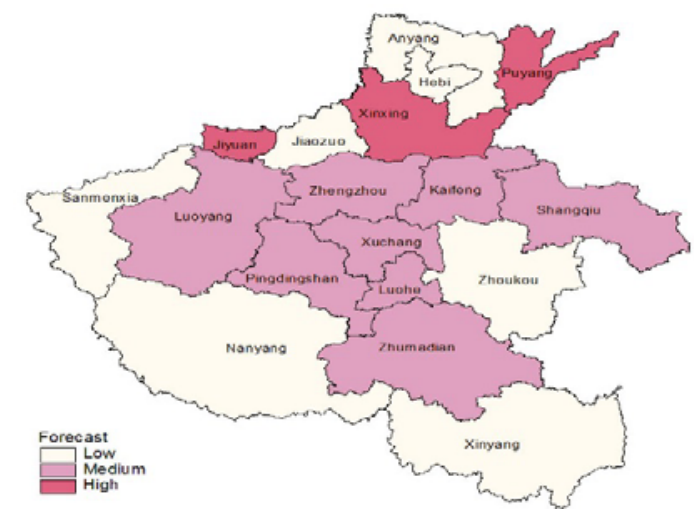

FIGURE III. THE FORECAST OF URBANIZATION GROWTH RATES (2016-2020)

Henan is an agricultural and populous province, land resource per capita share is less than the national average. In order to meet the food needs and the basic farmland protection requirements, agricultural population should be higher than other regions of the country. With the country as a reference, the reasonable range of province urbanization environmental loading, that is urbanization growth rates peak, should be between $75-80[10,11]$, therefore, they as the interval control volume are involved in the analysis.

From Table III, it can be seen, there is a certain promotion space between environmental loading and environmental endurance, which makes the urbanization growth rates improving is possible. All positive natural growth rates indicate that the urbanization growth rates have downward trends, in which Xinxiang is the maximum, Hebi is minimum. In the next 5 years, the urbanization levels will continue to rise rapidly, but the growth rates significantly slower than the past 5 years.

From the view of spatial distribution (Figure III), the distribution characteristics of the urbanization growth rates are opposite with the past 5 years. In the next 5 years, the cities with faster urbanization growth rates are mainly located in the central regions of the province. Jiyuan, Xinxiang and Puyang will keep high rates.

According to Henan national economic and social development of the 13th Five-Year year plan, by 2020 the province urbanization level will reach up to $56 \%$, the urbanization growth rate should keep $1.83 \%$ per year. So, according to the natural laws of the early urbanization development, in order to achieve the planning objectives, some specific measures, such as large-scale agricultural production, rapidly developing urban economy, adjusting the town layout, diverting more labor from the primary sector to secondary and tertiary industries, should be established.

\section{CONCLUSIONS}

By the empirical research of urbanization growth rates from 2011--2015 in Henan, this paper analyzes the geospatialtemporal characteristics and evolution patterns of urbanization growth rates in panoramic view.

Overall, the urbanization growth rates of all cities are gradually slowing down, there have been rapid increasing in a few local regions, but the overall distributions are tending to balance. In the 4 periods, the urbanization growth rates and the urbanization levels is inverse proportion, the urbanization growth rates of Zhengzhou, the provincial capital city, have been less than that of other cities. The spatial distributions of urbanization growth rates show north-south high and intermediate low, and gradually converging from north and south regions toward each other. In the next five years, the province urbanization growth rates of environmental loading and environmental endurance exist certain promotion space, the urbanization levels will continue to maintain a rapid growth, the growth rates will be slow down comparing with the past five years. There are some certain gaps in the natural growth rates and Thirteen Five Planning Objectives of the province.

\section{REFERENCES}

[1] X. Kuixi, Y. Yan, L. Hui, "Study on enhancing radiation of New York and the reference for guangzhou .” Urban Insight, pp.50-56, May 2013.

[2] Y. Shimou, Z. Pingyu, "The Theory and Practice of New Urbanization in China.” Scientia geographica Sinica, vol. 34, pp. 641-647, April 2014.

[3] L. Qiang, C. Yulin, L. Jingming, "On the development of Chinese urbanization.” Social Sciences in China, pp. 82-100, July 2012.

[4] L. Xueqin, W. Dai, R. Wangbing, "Research on the mechanism of urbanization to economic increase in China.” Geographical Research, vol. 32, pp. 691-700, April 2013.

[5] J. Ming, Z. Weiwei, "The Regional Characteristics of the Population Flow in China and its Influence on the Urbanization.” Journal of Guangxi Teachers Education University(Natural Science Edition), vol. 32, pp. 1-9, February , 2016. 
[6] M. Wei, B. Yongping, Z. Yonghua, "Spatial Pattern and Convergence of New Urbanization in China: 2002-2011.” Economic Geography, vol. 35, pp. 62-72, February, 2015.

[7] J. Wei, "The spatial econometrical analysis to influencing factors of Chinese regional urbanization level.”Economic Geography, vol. 39, pp. 613 - 616, April, 2009.

[8] Z. Kaiguang, B. Mingting, S. Yanming, "Study on Spatial Distribution characteristics of Intra-City Agriculture Sub-sector Value-Added Growth Rates in Henan Province.” .Advances in engineering research, vol. 33, pp. 167-171, 2015.

[9] Z. Kaiguang, "Estimation of parameter function in log-normal distribution. ” Xianmen university,1990.

[10] Z. Yan, H. Zhilong, "Re-evalution on the level and pace of China's urbanization.” Urban studies, vol. 17, pp. 1-6, November, 2010.

[11] MA Wei, BA Yongping, "Spatial pattern and convergence of new urbanization in China:2002-2011. Economic Geography, vol.35, pp. 6270, February, 2015. 